\title{
Predictors of Self-mutilation in Patients with Borderline Personality Disorder: A 10-Year Follow-up Study
}

\author{
Mary C. Zanarini, Ed.D. ${ }^{1,2}$, Corina S. Laudate, B.A. ${ }^{1}$, Frances R. Frankenburg, M.D. ${ }^{1,3}$, D. \\ Bradford Reich, M.D. ${ }^{1,2}$, and Garrett Fitzmaurice, Sc.D. ${ }^{1,2}$ \\ ${ }^{1}$ McLean Hospital, Belmont, MA \\ ${ }^{2}$ Harvard Medical School, Boston, MA \\ ${ }^{3}$ Boston University School of Medicine, Boston, MA
}

\begin{abstract}
Background-Self-mutilation is a common and serious problem in patients with borderline personality disorder (BPD). The purpose of this study was to determine the most clinically relevant baseline and time-varying predictors of self-mutilation over 10 years of prospective follow-up among patients with BPD.
\end{abstract}

Method-Four semi-structured interviews assessing axis I disorders, childhood adversity, adult experiences of abuse, and experiences of self-mutilation were administered at baseline to 290 patients meeting DIB-R and DSM-III-R criteria for BPD. Three of these interviews (all except for the childhood adversity interview) and two self-report measures pertaining to dysphoric affects and cognitions were administered at each of five contiguous two-year follow-up periods.

Results-Eleven variables were found to be significant bivariate predictors of self-mutilation over the five follow-up periods. Six of these predictors remained significant in multivariate analyses: female gender, severity of dysphoric cognitions (mostly overvalued ideas), severity of dissociative symptoms, major depression, history of childhood sexual abuse, and sexual assaults as an adult.

Conclusions-Taken together, the results of this study suggest that factors pertaining to traumatic experiences throughout the lifespan are significant risk factors for self-mutilation over time. These results also suggest that major depressive episodes and cognitive symptoms, particularly overvalued ideas and dissociation, significantly heighten the risk of self-injurious behaviors tracked for a decade.

\section{Keywords}

borderline personality disorder; self-mutilation; longitudinal course

\footnotetext{
(C) 2010 Elsevier Ltd. All rights reserved.

Address reprint requests to Dr. Zanarini, McLean Hospital, 115 Mill Street, Belmont, Massachusetts 02478; phone: 617-855-2660; fax: 617-855-3580; zanarini@mclean.harvard.edu..

Publisher's Disclaimer: This is a PDF file of an unedited manuscript that has been accepted for publication. As a service to our customers we are providing this early version of the manuscript. The manuscript will undergo copyediting, typesetting, and review of the resulting proof before it is published in its final citable form. Please note that during the production process errors may be discovered which could affect the content, and all legal disclaimers that apply to the journal pertain.
} 


\section{Introduction}

Self-mutilation is a common and serious symptom of borderline personality disorder (BPD) (Dulitt et al., 1994; Sabo et al., 1995; Soloff et al., 1994; Zanarini et al., 1990). Crosssectional studies have found that childhood adversity is significantly associated with selfmutilation in patients with BPD (Dubo et al., 1997; Zanarini et al., 2002). Cross-sectional studies have also found that suicidal ideation, previous suicide attempts, and dissociative symptoms are significantly related to their self-mutilatory efforts (Dulitt et al., 1994; Soloff et al., 1994). Still other cross-sectional studies have found that borderline patients commonly report that they mutilate themselves to gain relief from negative emotions (Brown et al., 2002; Hulbert \& Thomas, 2010). However, to the best of our knowledge, no study has assessed the predictors of self-mutilation over time. The current study assesses this relationship over a decade of prospective follow-up in a large sample of carefully diagnosed patients with BPD. We studied most of the predictors mentioned by others but added additional predictors thought by our group to be clinically relevant (e.g., severity of dysphoric inner states, substance abuse, major depression).

\section{Methods}

\subsection{Procedures}

The methodology of this study, which was reviewed and approved by the McLean Hospital Institutional Review Board, has been described in detail elsewhere (Zanarini et al., 2003). Briefly, all subjects were initially inpatients at McLean Hospital in Belmont, Massachusetts. Each patient was first screened to determine that he or she: 1) was between the ages of 18-35; 2) had a known or estimated IQ of 71 or higher; 3) had no history or current symptoms of schizophrenia, schizoaffective disorder, bipolar I disorder, or an organic condition that could cause psychiatric symptoms; and 4) was fluent in English.

After the study procedures were explained, written informed consent was obtained. Each patient then met with a masters-level interviewer blind to the patient's clinical diagnoses for a thorough diagnostic assessment. Three semistructured diagnostic interviews were administered. These diagnostic interviews were: 1) the Structured Clinical Interview for DSM-III-R Axis I Disorders (SCID-I), (Spitzer et al., 1992) 2) the Revised Diagnostic Interview for Borderlines (DIB-R), (Zanarini et al., 1989) and 3) the Diagnostic Interview for DSM-III-R Personality Disorders (DIPD-R). (Zanarini et al., 1987) The inter-rater and test-retest reliability of all three of these measures have been found to be good-excellent (Zanarini \& Frankenburg, 2001; Zanarini, Frankenburg, \& Vujanovic, 2002).

Three other semistructured interviews were also administered at baseline. These interviews were: the Lifetime Self-destructiveness Scale (LSDS) (Zanarini et al., 2006), the Abuse History Interview (AHI) (Zanarini et al., 2005), and the Revised Childhood Experiences Questionnaire (CEQ-R) (Zanarini et al., 1997). The interrater and test-retest reliability of these interviews have also been found to be good-excellent (Zanarini et al., 2005, Zanarini et al., 1997).

At each of five follow-up waves, separated by 24 months, axis I and II psychopathology was reassessed via interview methods similar to the baseline procedures by staff members blind to baseline diagnoses. After informed consent was obtained, our diagnostic battery was readministered (with the SCID I focusing on the past two years and not as at baseline, lifetime axis I psychopathology). The follow-up interrater reliability (within one generation of follow-up raters) and follow-up longitudinal reliability (from one generation of raters to the next) of these three measures have been found to be good-excellent (Zanarini \& Frankenburg, 2001; Zanarini, Frankenburg, \& Vujanovic, 2002). 
The follow-up versions of the LSDS and the AHI were also administered at each of the study's five follow-up periods. The follow-up interrater reliability and follow-up longitudinal reliability of these two measures have also been found to be good-excellent (Zanarini et al., 2006; Zanarini et al., 2005).

In addition, the Dysphoric Affect Scale, a 50-item self-report measure, was administered at each of the study's five follow-up periods (Zanarini et al., 1998). The DAS assesses 50 affects or cognitions that represent the inner states typical of borderline patients. The measure has been found to have good internal consistency as well as test-retest reliability. The DES, a 28-item self-report, measuring the severity of dissociative experiences was also administered at each of these five waves of follow-up (Zanarini et al., 2008). The DES has been found to have good test-retest and split-half reliability (Bernstein \& Putnam, 1986). It has also been found to have construct and criterion validity. Both of these self-report measures ask subjects to rate the percentage of the time that each inner state is experienced, with a range of $0-100 \%$.

\subsection{Participants}

Two hundred and ninety patients met both DIB-R and DSM-III-R criteria for BPD. In terms of baseline demographic data, $80.3 \%(\mathrm{~N}=233)$ of the subjects were female and $87.2 \%$ $(\mathrm{N}=253)$ were white. The average age of the borderline subjects was 26.9 years $(\mathrm{SD}=5.8)$, their mean socioeconomic status was $3.4(\mathrm{SD}=1.5)$ (where 1=highest and 5=lowest), and their mean GAF score was 38.9 ( $\mathrm{SD}=7.5$ ) (indicating major impairment in several areas, such as work or school, family relations, judgment, thinking, or mood).

In terms of continuing participation, 275 borderline patients were reinterviewed at two years, 269 at four years, 264 at six years, 255 at eight years, and 249 at ten years. At the tenyear assessment, 41 borderline patients were no longer in the study: 12 had committed suicide, seven died of other causes, nine discontinued their participation, and 13 were lost to follow-up. All told, 91.9\% ( $\mathrm{N}=249 / 271)$ of surviving borderline patients were reinterviewed at all five follow-up waves.

\subsection{Statistical Analyses}

Generalized estimating equations (GEE) were used in longitudinal analyses of the predictors of the prevalence of self-mutilation. These analyses modeled the log odds (or logit of the prevalence) of self-mutilation, yielding an odds ratio (OR), and 95\% confidence interval $(95 \% \mathrm{CI})$, for the association with a given predictor; analyses also appropriately accounted for the correlation among the repeated measures of self-mutilation. In carrying out the analyses summarized in this report, we first assessed the relationship between each baseline and time-varying predictor variable and the presence of self-mutilation, while controlling for assessment period. Next, to select the subset of predictors to be retained in the most parsimonious multivariate model, we compared a sequence of models in a step-down manner. In these models, assessment period was always included as a covariate to allow for temporal variation in the prevalence of self-mutilation. This selection procedure started with the significant bivariate factors and stepped down to the most parsimonious model on the basis of tests of significance of the predictors in the model.

Categorical data are reported as \% (N); averaged continuous data are reported as means with standard errors of the means (SE). Statistical significance required 2-tailed $\mathrm{p}<0.05$.

\section{Results}

Our outcome was the presence/absence of at least one episode of self-mutilation at each of the study's five follow-up periods. Self-mutilation was defined as any intentional self- 
inflicted injury without intent to die (e.g., punching, cutting. or burning oneself). The following prevalence figures were found: $50.9 \%(\mathrm{~N}=140)$ at two-year follow-up, 35.3\% $(\mathrm{N}=95)$ at four-year follow-up, $28.4 \%(\mathrm{~N}=75)$ at six-year follow-up, $22.4 \%(\mathrm{~N}=57)$ at eightyear follow-up, and $17.5 \%(\mathrm{~N}=44)$ at 10 -year follow-up.

In terms of baseline predictors, we selected these 14 variables based on our review of the cross-sectional literature and our collective clinical experience. All told, $62.4 \%(\mathrm{~N}=181)$ of participants reported a childhood history of sexual abuse. Severity of other forms of childhood abuse was found to have a mean of $7.3(\mathrm{SE}=0.31)$ (range=0-18), while severity of neglect was found to have a mean of $14.7(\mathrm{SE}=0.63)$ (range=0-42).

In terms of time-varying predictors, Figure1 presents the means (SE) for the DAS and the DES at two-year follow-up through 10-year follow-up. Figure 2 presents the prevalence of major depression and substance abuse at the same five time points, while Figure 3 presents the prevalence of being the victim of sexual or physical assault as an adult at these five time periods. (Each of these time-varying variables predicted self-mutilation occurring in the same time period as the predictor occurred. For example, major depression during the two years from two to four year follow-up was studied as a predictor of self-mutilation during the same two-year period.)

Table 1 presents the bivariate predictors of self-mutilation across the five follow-up periods. (Each row represents a separate analysis for each predictor that also controlled for the effect of time.) As can be seen, 11 of these variables were found to be significant in these analyses. These 11 variables were: female gender, mean DAS affect score, mean DAS cognition score (mostly overvalued ideas, such as I am evil or I am damaged beyond repair), mean DES score, major depression, childhood history of sexual abuse, severity of childhood history of other abuse, severity of childhood history of neglect, adult sexual assault, adult physical assault, and lifetime number of episodes of self-mutilation at baseline.

Given the complexity of the analyses, we believe that several examples would be helpful for interpreting the results in Table 1. The odds of self-mutilation over time are 2.67 times higher for subjects who reported a childhood history of sexual abuse at baseline (relative to those who did not). In a like manner, having been raped as an adult increased the odds of self-mutilation over time by a factor of approximately 2 . As an example of a continuous predictor variable, for each five-point increase in severity of other forms of childhood abuse, the odds of self-mutilation over time increases by $21 \%$. For each 10-point increase in the mean DAS affect score (e.g., moving from $40 \%$ of the time to $50 \%$ of the time), the odds of self-mutilation over time increases by $30 \%$.

Table 2 presents the multivariate predictors of self-mutilation across the five time periods. Six variables were found to significantly predict self-mutilation in this joint analysis: female gender, severity of dysphoric cognitions (mostly overvalued ideas), severity of dissociative symptoms, major depression, history of childhood sexual abuse, and sexual assaults as an adult.

As a partial check on circularity, we repeated these bivariate and multivariate analyses using only baseline (childhood predictors) and two-year predictors (e.g., mean DES score, physical assault at that time point). We found basically the same results and this is supportive of the assumed direction of the relationship between predictors and outcome.

\section{Discussion}

Four main findings have emerged from this study. The first is that bivariate predictive factors associated cross-sectionally with self-mutilation also predict self-mutilation over 10 
years of prospective follow-up. More specifically, we found that the severity of childhood experiences of abuse and neglect as well as the severity of dissociative experiences and the presence of episodes of major depression were associated with self-mutilation over time.

The second main finding, which also pertains to bivariate predictors, is that a history of being the victim of adult violence is associated with self-mutilation over time. More specifically, having reported a history of rape as an adult and/or a history of having a physically assaultive partner or spouse is associated with on-going self-mutilatory episodes.

Our third main finding, which too pertains to bivariate predictors, is that severity of dysphoric affects and dysphoric cognitions other than dissociation reported by borderline patients are both bivariate predictors significantly associated with the longitudinal course of self-mutilatory behaviors. More specifically, dysphoric affects (which often co-occurred) and dysphoric cognitions (mainly overvalued ideas of being bad or damaged) were longitudinally predictive of the presence of self-mutilatory acts across the waves of followup, suggesting that the chronic inner states of borderline patients are important to address in efforts to help borderline patients stop mutilating themselves. The affective aspect of this finding is consistent with the prior finding that borderline patients commonly report deliberately hurting themselves physically to relieve negative feelings (Brown et al., 2002; Hulbert \& Thomas, 2010).

Our fourth finding is that most of the factors that were significant in bivariate analyses remained significant when considered jointly in multivariate analyses: female gender, DAS cognition score, DES score, presence of major depression, history of childhood sexual abuse, and adult sexual assault. It is not surprising that being female is a predictor of episodes of self-mutilation as it has previously been found that self-harm is more common over time among women than men with BPD (Zanarini et al., 2003). It is a new finding that the severity of overvalued ideas of being bad heightens the risk of self-mutilation over time. This finding suggests that firmly held negative beliefs about the self, which might be intensified by either interpersonal disappointments or concurrent major depressive episodes, are an important predictor of the likelihood that a borderline patient will engage in selfmutilation over time.

Dissociation has long been associated with the borderline diagnosis. At times, it is seen as a core symptom of BPD (Zanarini, Gunderson, \& Frankenburg, 1990) with a strong heritable component (Jang et al., 1998). At other times, it is seen as a way of coping with the stress inherent in childhood sexual abuse or adult sexual assault (Herman \& van der Kolk, 1987). Regardless of its etiology, it seem that being disengaged from one's feelings heightens the risk that a person with BPD will engage in self-mutilation at some point over a decade of prospective follow-up.

Our final multivariate predictors of self-mutilation over time are childhood sexual abuse and adult sexual assault. These findings, while important, need to be placed in context. More specifically, these factors are associated with a heightened risk of self-mutilation over time. These results do not mean that all borderline patients who mutilated themselves over time had a history of childhood sexual abuse, adult sexual assault, or both. Nor do they mean that all borderline patients who reported childhood and/or adult sexual abuse or assault deliberately hurt themselves physically over the course of the study.

However, five significant bivariate predictors were not significant in our multivariate model: DAS affect score, severity of other forms of childhood abuse, severity of childhood neglect, adult experiences of being physically assaulted by a partner or spouse, and lifetime number of episodes of self-mutilation. At first glance, it seems surprising that dysphoric affects would not be a significant multivariate risk factor for episodes of self-mutilation. But our 
results seem to suggest that painful overvalued ideas and the numbing effects of dissociation are substantially stronger risk factors than dysphoric affects, perhaps because they are more stable inner states than affects, which tend to be more reactive in nature. In addition, the presence of one or more episodes of major depression in a follow-up period may have subsumed some of the predictive power of our continuous measure of affective dysphoria.

It also seems surprising that the severity of non-sexual forms of childhood abuse and the severity of childhood neglect are not significant multivariate predictors of self-mutilation over time. This is particularly so because we had previously found a cross-sectional relationship between these variables in this study (Zanarini et al., 2002). However, it may be that the effects of other forms of childhood abuse and childhood neglect attenuate over time or at least their effects may attenuate more over time than the effects of childhood sexual abuse.

The lack of a significant multivariate relationship between adult experiences of physical abuse and self-mutilation over time does not seem particularly surprising. This is so partly because no cross-sectional study has found a significant link between childhood physical abuse and a history of self-mutilation (Zanarini et al., 2002). This is also so because these abandonment-sensitive patients may interpret the actions of physically abusive partners or spouses as a sign of intense involvement that mitigates the need for the indirect communication inherent in self-mutilation (Hooley \& Hoffman, 1999).

Finally, lifetime number of episodes of self-mutilation reported at baseline failed to be a significant multivariate predictor of self-mutilation over time for borderline patients. The reasons for this are not clear. It may be that predictors closer in time to episodes of selfmutilation during the decade of prospective follow-up (i.e., time-varying predictors such as major depressive episodes) are stronger predictors of ongoing self-mutilation. It may also be that the pattern of self-mutilation engaged in prior to index admission was already waning for some patients.

This study has two main limitations. One limitation of this study is that all of the patients were seriously ill inpatients at the start of the study. Another limitation is that about $90 \%$ of patients were in individual therapy and taking psychotropic medications at baseline and about $70 \%$ were participating in each of these outpatient modalities during each follow-up period (Hörz et al., 2010). Thus, it is difficult to know if these results would generalize to a less disturbed group of patients or people meeting criteria for BPD who are not in treatment.

\section{Conclusions/Implications}

Taken together, the results of this study suggest that factors pertaining to traumatic experiences throughout the lifespan are associated with self-mutilation over time. These results also suggest that major depressive episodes and cognitive symptoms, particularly overvalued ideas and dissociation, are associated with self-injurious behaviors tracked for a decade.

\section{References}

Bernstein EM, Putnam FW. Development, reliability, and validity of a dissociation scale. Journal of Nervous and Mental Disease. 1986; 174:727-735. [PubMed: 3783140]

Brown MZ, Comtois KA, Linehan MM. Reasons for suicide attempts and nonsuicidal self-injury in women with borderline personality disorder. Journal of Abnormal Psychology. 2002; 111:198-202. [PubMed: 11866174]

Dubo ED, Zanarini MC, Lewis RE, Williams AA. Childhood antecedents of self-destructiveness in borderline personality disorder. Canadian Journal of Psychiatry. 1997; 42:63-69. 
Dulit RA, Fyer MR, Leon AC, Brodsky BS, Frances AJ. Clinical correlates of self-mutilation in borderline personality disorder. American Journal of Psychiatry. 1994; 152:1305-1311. [PubMed: 8067485]

Herman, JL.; van der Kolk, BA. Traumatic antecedents of borderline personality disorder, in Psychological Trauma. van der Kolk, BA., editor. American Psychiatric Press; Washington, DC: 1987. p. 111-126.

Hurlbert C, Thomas R. Predicting self-injury in BPD: an investigation of the experiential avoidance model. Journal of Personality Disorders. 2010; 24:651-663. [PubMed: 20958173]

Hooley JM, Hoffman PD. Expressed emotion and clinical outcome in borderline personality disorder. American Journal of Psychiatry. 1999; 156:1557-1562. [PubMed: 10518166]

Hörz S, Zanarini MC, Frankenburg FR, Reich DB. Ten-year use of mental health services by patients with borderline personality disorder and with other axis II disorders. Psychiatric Services. 2010; 61:612-616. [PubMed: 20513685]

Jang KL, Paris J, Zweig-Frank H, Livesley WJ. Twin study of dissociative experience. Journal of Nervous and Mental Disease. 1998; 186:345-351. [PubMed: 9653418]

Sabo AN, Gunderson JG, Najavits LM, Chauncey D, Kisiel C. Changes in self-destructiveness of borderline patients in psychotherapy: a prospective follow-up study. Journal of Nervous and Mental Disease. 1995; 183:370-376. [PubMed: 7798085]

Soloff PH, Lis JA, Kelly T, Cornelius J, Ulrich R. Self-mutilation and suicidal behavior in borderline personality disorder. Journal of Personality Disorders. 1994; 8:257-267.

Spitzer RL, Williams JB, Gibbon M, First MB. Structured Clinical Interview for DSM-III-R (SCID). I: history, rational, and description. Archives of General Psychiatry. 1992; 49:624-629. [PubMed: 1637252]

Zanarini MC, Frankenburg FR. Attainment and maintenance of reliability of axis I and II disorders over the course of a longitudinal study. Comprehensive Psychiatry. 2001; 42:369-374. [PubMed: 11559863]

Zanarini MC, Frankenburg FR, Chauncey DL, Gunderson JG. The Diagnostic Interview for Personality Disorders: inter-rater and test-retest reliability. Comprehensive Psychiatry. 1987; 28:467-480. [PubMed: 3691072]

Zanarini MC, Frankenburg FR, DeLuca CJ, Hennen J, Khera GS, Gunderson JG. The pain of being borderline: dysphoric states specific to borderline personality disorder. Harvard Review of Psychiatry. 1998; 6:201-207. [PubMed: 10370445]

Zanarini MC, Frankenburg FR, Hennen J, Silk KR. The longitudinal course of borderline psychopathology: 6-year prospective follow-up of the phenomenology of borderline personality disorder. American Journal of Psychiatry. 2003; 160:274-283. [PubMed: 12562573]

Zanarini MC, Frankenburg FR, Jager-Hyman S, Reich DB, Fitzmaurice G. The course of dissociation for patients with borderline personality disorder and axis II comparison subjects: a 10-year followup study. Acta Psychiatrica Scandanavica. 2008; 118:291-296.

Zanarini MC, Frankenburg FR, Reich DB, Hennen J, Silk KR. Adult experiences of abuse reported by borderline patients and axis II comparison subjects over six years of prospective follow-up. Journal of Nervous and Mental Disease. 2005; 193:412-416. [PubMed: 15920382]

Zanarini MC, Frankenburg FR, Ridolfi ME, Jager-Hyman S, Hennen J, Gunderson JG. Reported childhood onset of self-mutilation among borderline patients. Journal of Personality Disorders. 2006; 20:9-15. [PubMed: 16563075]

Zanarini MC, Frankenburg FR, Vujanovic AA. The inter-rater and test-retest reliability of the Revised Diagnostic Interview for Borderlines (DIB-R). Journal of Personality Disorders. 2002; 16:270_ 276. [PubMed: 12136682]

Zanarini MC, Gunderson JG, Frankenburg FR. Cognitive features of borderline personality disorder. American Journal of Psychiatry. 1990; 147:57-63. [PubMed: 2293789]

Zanarini MC, Gunderson JG, Frankenburg FR, Chauncey DL. The Revised Diagnostic Interview for Borderlines: discriminating BPD from other axis II disorders. Journal of Personality Disorders. $1989 ; 3: 10-18$. 
Zanarini MC, Gunderson JG, Frankenburg FR, Chauncey DL. Discriminating borderline personality disorder from other axis II disorders. American Journal of Psychiatry. 1990; 147:161-167. [PubMed: 2301653]

Zanarini MC, Yong L, Frankenburg FR, Hennen J, Reich DB, Marino M. Severity of reported childhood sexual abuse and its relationship to severity of borderline psychopathology and psychosocial impairment. Journal of Nervous and Mental Disease. 2002; 190:381-387. [PubMed: 12080208]

Zanarini MC, Williams AA, Lewis RE, Reich RB, Vera SC, Marino MF, Levin A, Yong L, Frankenburg FR. Reported pathological childhood experiences associated with the development of borderline personality disorder. American Journal of Psychiatry. 1997; 154:1101-1106. [PubMed: 9247396] 


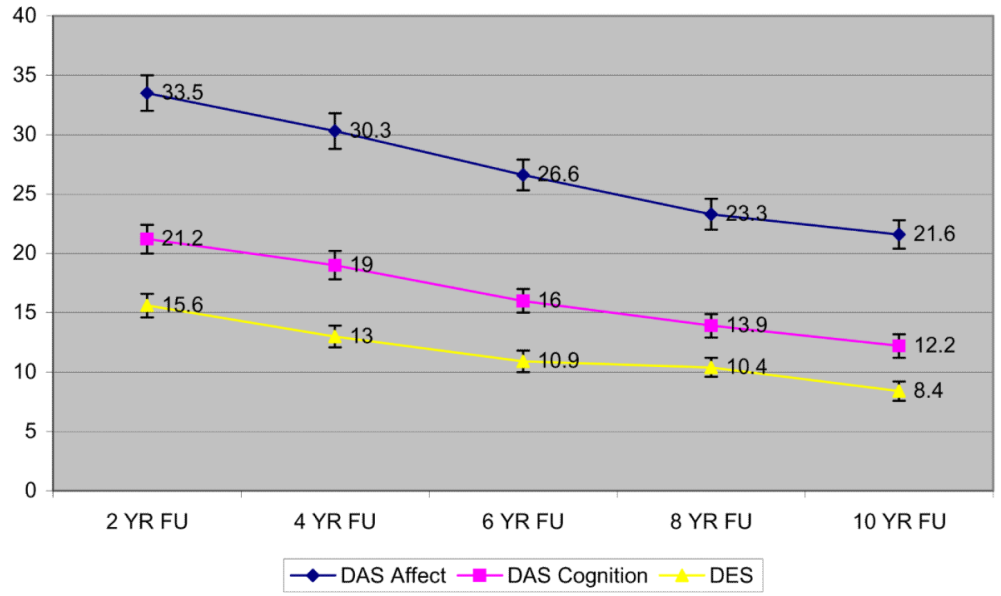

Figure 1.

Mean DAS and DES Scores Over Time 


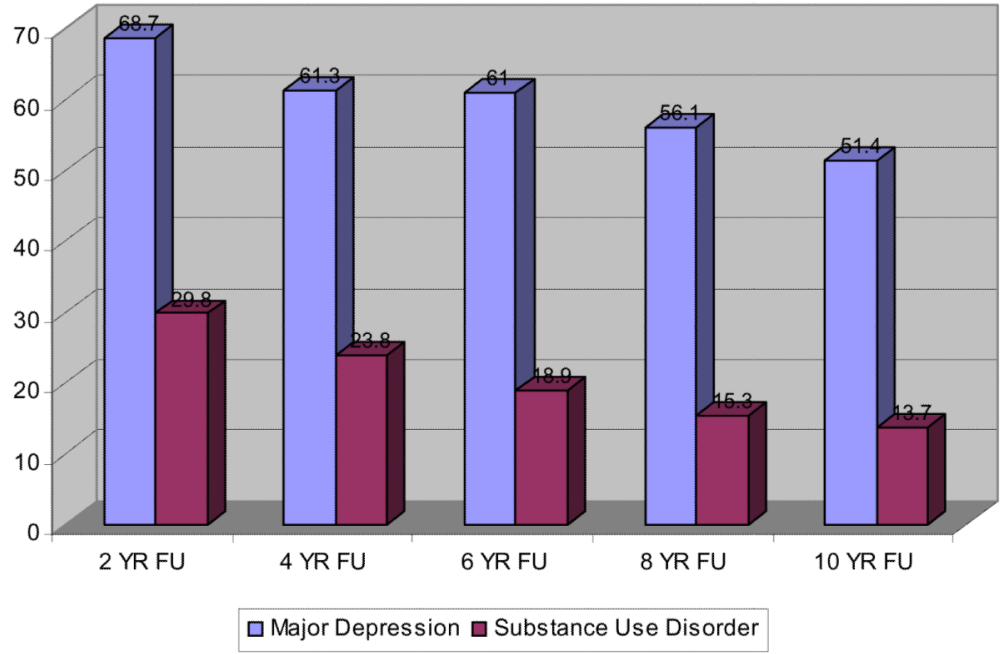

Figure 2.

Prevalence of Selected Axis I Disorders Over Time 


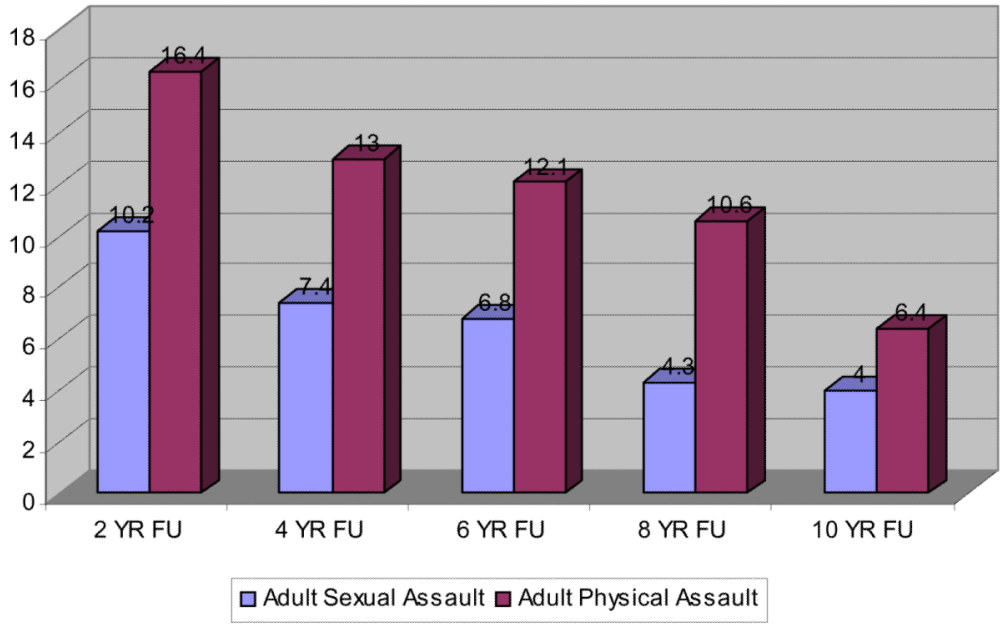

Figure 3.

Prevalence of Adult Sexual and Physical Assault Over Time 


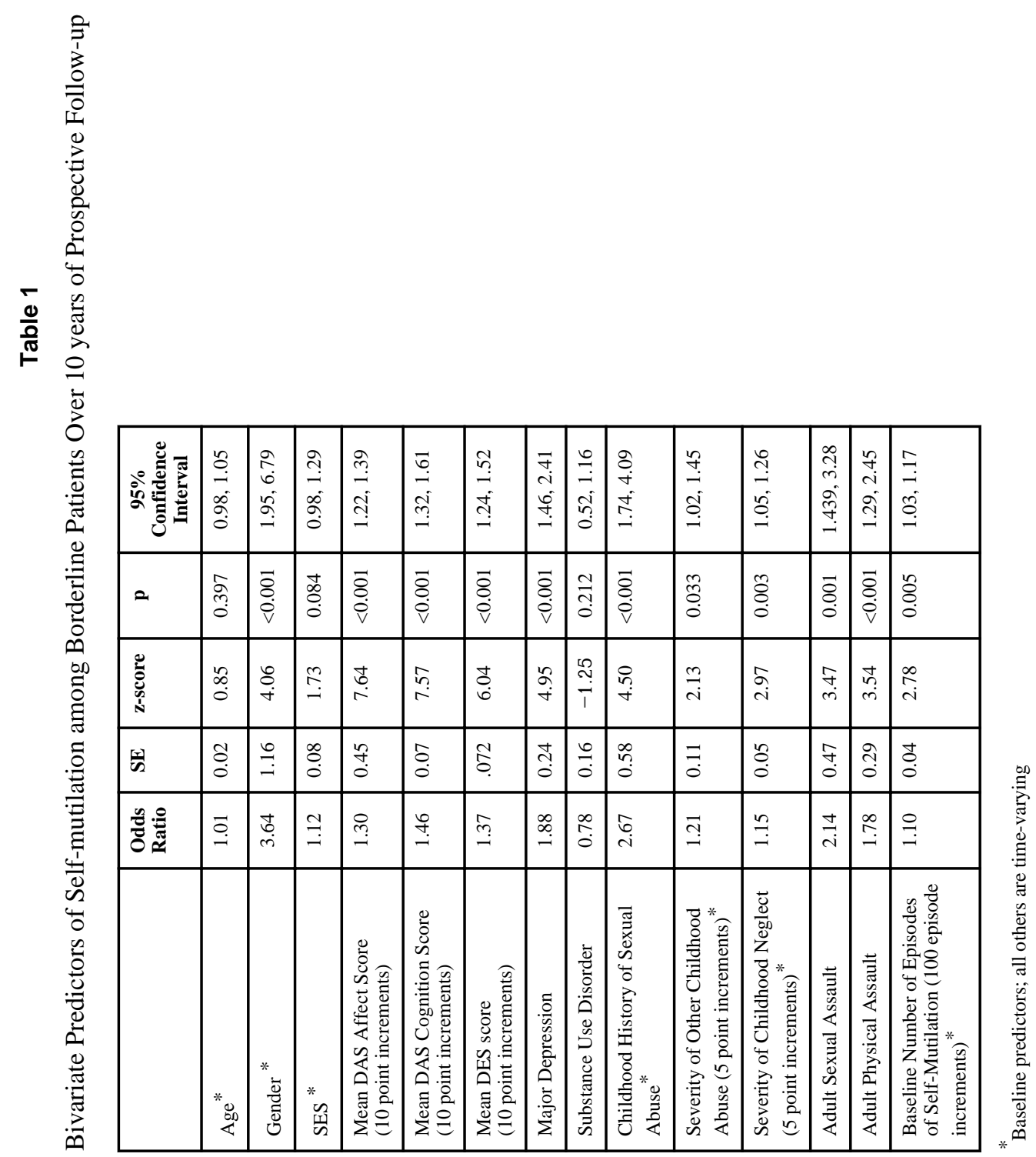

J Psychiatr Res. Author manuscript; available in PMC 2012 June 1. 


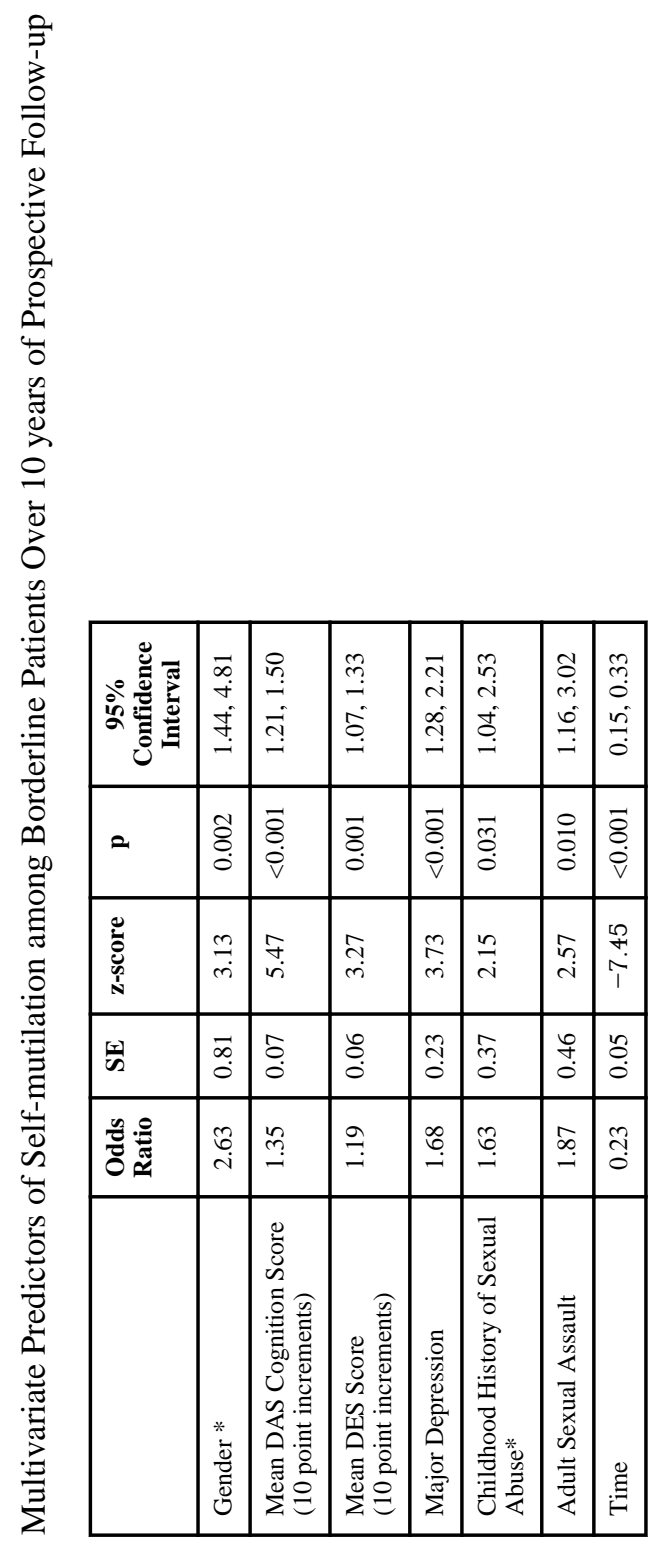

J Psychiatr Res. Author manuscript; available in PMC 2012 June 1. 